ARTIGO

\title{
A gestão democrática nos sistemas municipais de ensino do Paraná: uma análise a partir dos conselhos municipais de educação
}

Simone de Fátima Flach a

\section{Resumo}

Este texto discute a gestão democrática nos Conselhos Municipais de Educação dos municípios paranaenses que constituíram sistemas próprios de Ensino e tem, por objetivo, demonstrar como os órgãos normativos são compostos, as possibilidades e os limites para a participação democrática nos contextos locais. Para tanto, tendo como pressuposto teórico e metodológico o materialismo histórico e dialético, o artigo discute a autonomia municipal para condução da educação sob sua responsabilidade e analisa a composição dos Conselhos Municipais de Educação dos municípios que já instituíram sistemas próprios de Ensino. As análises evidenciam que a composição dos Conselhos Municipais de Educação se caracteriza como possibilidade de exercício democrático, mas os limites também se fazem presentes, indicando vinculação com os interesses hegemônicos que orientam as políticas locais.

Palavras-chave: Sistema Municipal de Ensino. Conselhos Municipais de Educação. Gestão democrática. Políticas Educacionais.

\section{Introdução}

Este texto, derivado de pesquisa mais ampla ${ }^{1}$, que analisa o quadro normativo e as condições político-institucionais relativos à gestão democrática do ensino público no âmbito dos Sistemas Municipais de Ensino (SME) no estado do Paraná, tem por objetivo demonstrar como os órgãos normativos estão organizados e quais as possibilidades e os limites para a efetivação da participação democrática

\footnotetext{
a Universidade Estadual de Ponta Grossa, Ponta Grossa, PR, Brasil.

Pesquisa intitulada "Gestão democrática no ensino público paranaense e sua relação com as determinações da sociedade regida pelo capital: uma análise a partir dos sistemas municipais de ensino legalmente constituídos", desenvolvida durante o Pós-doutoramento da autora, junto à Universidade Tuiuti do Paraná - UTP, sob a supervisão da Prof. Dra. Anita Helena Schlesener.
} 
na condução das políticas educacionais locais. Para tanto, expõe e analisa a composição de Conselhos Municipais de Educação (CME), tendo em vista sua abertura para a participação de diferentes representações das comunidades locais.

A discussão acerca da constituição de SME mostra-se relevante no contexto brasileiro, visto que, historicamente, houve uma centralização do poder governamental, de forma a desconsiderar a capacidade municipal para elaborar, conduzir e avaliar políticas de interesse local. Por isso, quando os municípios optam por constituir seus próprios SME, afirmam sua autonomia na condução das políticas educacionais sob sua responsabilidade, com vistas ao envolvimento da comunidade local nessa condução.

Nesse sentido, a opção por organizar sistema próprio de Ensino pode indicar capacidade organizativa interna dos governos municipais, devidamente articulada em prol de objetivos nacionais e abertura para que a comunidade se responsabilize pela condução das políticas locais. Assim, os SME, ao serem constituídos, representam avanços em relação ao princípio da gestão democrática do ensino público, que deve reger a administração político-administrativa do país.

A organização de SME é uma possibilidade legal que indica, potencialmente, para o desenvolvimento da autonomia dos municípios em gerir a educação local. No entanto, para além da previsão legal, a organização de SME está vinculada aos encaminhamentos políticos de cada estado da federação, ao compromisso dos gestores públicos municipais e, ainda, à compreensão coletiva sobre a emergência de envolvimento democrático nas escolhas educacionais, com vistas à melhoria da qualidade da educação, tanto no contexto municipal, quanto estadual e nacional.

Para tanto, o compromisso com os rumos educacionais insere-se na discussão sobre o exercício democrático, o qual possibilita a participação do sujeito e colabora na concretização da cidadania para além dos direitos e dos deveres individuais, em prol dos interesses coletivos. Entretanto, considera-se que, na atual forma de sociabilidade, o exercício da cidadania é tênue, visto que se baseia na universalidade dos direitos políticos, sem interferir nas relações que dão sustentação à exploração do homem pelo homem. Nesse sentido, o capitalismo “[...] torna possível uma forma de democracia em que a igualdade formal de direitos políticos tem efeito mínimo sobre as desigualdades ou sobre as relações de dominação e de exploração em outras esferas" (WOOD, 2006, p. 193), deixando intacta a lógica da exploração de uma classe sobre a outra. Portanto, a democracia, nos limites da sociedade capitalista, possibilita a coexistência da liberdade e igualdade jurídica, da exploração de classe e, consequentemente, da desigualdade social. 
Entretanto, ao criarem-se mecanismos de participação coletiva, que privilegiem todos os segmentos da sociedade (em especial aqueles mais afeitos às decisões a serem tomadas), a organização de CME pode colaborar para o que Gramsci (2007) chama de "vontade coletiva" e contribuir para uma educação democrática, que tenha como objetivo atingir a todos, sem qualquer privilégio de classe.

E é preciso também definir a vontade coletiva e a vontade política em geral no sentido moderno, a vontade como consciência operosa da necessidade histórica, como protagonista de um drama histórico real e efetivo.

Uma das primeiras partes deveria precisamente ser dedicada à "vontade coletiva", apresentando a questão do seguinte modo: quando é possível dizer que existem as condições para se criar e se desenvolver uma vontade coletiva nacional-popular'²? (GRAMSCI, 2007, p. 17).

Dessa forma, o CME, como órgão do Estado e composto por diferentes segmentos da sociedade civil pode (ou não) interferir nos interesses que orientam as políticas públicas, dependendo da correlação de forças existentes em seu interior e nas possibilidades democráticas asseguradas na legislação. Por isso, a análise da organização e do funcionamento desses órgãos pode indicar em que medida a educação está sendo orientada pelo princípio constitucional de gestão democrática, e como a luta pela hegemonia se faz presente nas proposições, nas discussões realizadas e nas decisões tomadas coletivamente. Assim:

Torna-se de fundamental importância pensar as relações democráticas que ocorrem no âmbito do Estado e das relações educacionais, a fim de evidenciar a formação dos indivíduos e os compromissos que se atribuem ao sistema educacional no sentido de dar os fundamentos teóricos e normativos necessários ao desempenho no mundo do trabalho e ao exercício da democracia (SCHLESENER, 2011, p. 176-177).

Em face dessas questões, a análise dos dados apresentada caracteriza-se como exposição da investigação realizada, não tendo a pretensão de encerrar-se em si mesma, mas a de oferecer subsídios teóricos e práticos que colaborem na compreensão dos vários determinantes que compõem a realidade histórica. Isso indica a emergência de mecanismos que possibilitem, de forma imediata, a

\footnotetext{
2 Vontade coletiva nacional-popular pode ser compreendida como aquela que expressa a necessidade e os interesses da maioria dos indivíduos que compõem determinada sociedade, ou seja, os trabalhadores.
} 
emancipação política dos sujeitos e que tenha como objetivo maior a emancipação humana, com vistas a uma sociedade justa para toda a humanidade.

O referencial teórico-metodológico que orienta a pesquisa e as análises apresentadas é o materialismo histórico e dialético, conforme proposto por Karl Marx, tendo as categorias contradição, totalidade e práxis como fios condutores para entender a gestão democrática no contexto da atual forma de sociabilidade. Ainda, segundo o mesmo referencial, o pensamento de Antonio Gramsci oferece importante contribuição para desvelar a luta pela hegemonia que ocorre no interior dos SME, visto que, segundo esse pensador, o exercício do poder resulta da articulação entre sociedade civil e sociedade política, e que a correlação de forças existentes nas relações de classe é apaziguada pela capacidade de domínio e direção de uma classe sobre a outra. Por isso, quando uma classe detém a hegemonia, consegue deter também o poder.

Isto significa que um grupo social, que tem sua própria concepção do mundo, ainda que embrionária, que se manifesta na ação e, portanto, de modo descontínuo e ocasional - isto é, quando tal grupo se movimenta como um conjunto orgânico -, toma emprestado a outro grupo social, por razões de submissão e subordinação intelectual, uma concepção que não é a sua, e a afirma verbalmente, e também acredita segui-la, já que a segue em "épocas normais", ou seja, quando a conduta não é independente e autônoma, mas sim submissa e subordinada (GRAMSCI, 2004, p. 97).

Essa reflexão auxilia-nos a entender como determinada classe assimila de forma pacífica (e sem crítica) determinada concepção de mundo, de maneira que a hegemonia dominante se fortaleça e se mantenha como única alternativa possível para a organização da vida. Nessa perspectiva, a hegemonia torna-se força coesiva dando unidade ao pensamento e conduzindo debates, escolhas e ações conforme interesses dominantes. Por isso, as relações no interior dos órgãos normativos dos Sistemas de Ensino são contraditórias e podem evidenciar que o princípio da gestão democrática assume diferentes interpretações, conforme interesses em disputa.

A efetivação da gestão democrática no contexto municipal, portanto, não pode ser analisada sem considerar que há uma luta para manter determinados interesses, explícitos ou não, na condução da sociedade. Entende-se que essa luta pela hegemonia se evidencia desde a organização dos CME e respectivas composições, conforme representação prevista em lei específica. 
Com base nessas questões, para a coleta de dados, mapeou-se a legislação sobre a constituição de SME e CME nos websites dos órgãos executivo e legislativo dos 399 municípios paranaenses. O foco da análise centrou-se nos CME de municípios que já constituíram SME no estado do Paraná. Esse recorte justifica-se em razão de que, com a constituição de SME, é necessária a existência de órgão normativo representado pelo CME.

\section{A autonomia municipal para a organização de seu Sistema de Ensino}

O fim do regime militar em meados dos anos de 1980 fortaleceu a ideia de que, finalmente, seria implantada uma democracia no Brasil. Esse pensamento foi corroborado pela promulgação da Constituição Federal em 1988, a qual inovou ao equipar União, Estados e Municípios como entes federados em igualdade político-administrativa quando previu em seu art. 18 que: "A organização políticoadministrativa da República Federativa do Brasil compreende a União, os Estados, o Distrito Federal e os Municípios, todos autônomos, nos termos desta Constituição" (SENADO FEDERAL, 1988, p. 21) e elevou os municípios a entes autônomos quanto estabeleceu, no inciso I do art. 30, que são competentes para "[...] legislar sobre os assuntos de interesse local" (SENADO FEDERAL, 1988, p. 31).

Lagares (2008) e Soares (2017) alertam que a autonomia dos municípios ocorre nos seguintes planos concomitantes: autonomia político-administrativa, autonomia jurídico-normativa/autolegislação e autonomia financeira/tributária. A autonomia político-administrativa dá-se pela organização do aparato governamental para o atendimento dos interesses locais, conforme previsto em Lei Orgânica, sem imposição hierárquica dos demais entes federados, desde que respeitados os preceitos constitucionais. A autonomia jurídico-normativa ocorre quando o município é capaz de editar leis próprias, conforme matérias de sua competência estabelecidas nas Constituições Federal e Estadual. A autonomia financeira/ tributária é a capacidade de gerir adequadamente os recursos de sua competência, sejam relativos aos tributos municipais ou transferências do Estado ou da União.

Em relação à educação, o grau de autonomia, conferido aos entes federados, assume força coesiva nas políticas para o setor quando o art. 211 estabeleceu que: "A União, os Estados, o Distrito Federal e os Municípios organizarão em regime de colaboração seus sistemas de ensino" (SENADO FEDERAL, 1988, p. 139). Esse dispositivo indica a necessidade de cooperação entre os entes federados para com a educação, visto que cada qual tem competências e responsabilidades específicas (e concomitantes) para o atendimento educacional no país. A esse respeito, Cury (2008) alerta que: 


\begin{abstract}
A atual Constituição deu continuidade à tradição advinda do Ato Adicional de 1834 e dispôs pela pluralização dos sistemas, inclusive pela incorporação dos sistemas de ensino municipais (art. 211).

Esses sistemas, coexistentes ao reconhecimento de estados, municípios, Distrito Federal e União como entes federativos, teriam uma articulação mútua organizada por meio de uma engenharia consociativa articulada por um regime de colaboração entre todos eles. Tal engenharia serviria como modo de se evitar a dispersão de esforços e como meio de se efetivar um regime federativo e cooperativo na educação escolar (p. 1199).
\end{abstract}

Nessa perspectiva, os "[...] sistemas de ensino desde logo passaram a usufruir existência legal, ficando a organização e o seu modo de funcionamento sob a esfera da autonomia dos entes federativos, obedecendo ao princípio da colaboração recíproca" (CURY, 2008, p. 1201). Dessa forma, a partir da Constituição Federal de 1988, o que orienta as relações entre os entes federados deve ser o pacto federativo, não havendo razões para relações hierárquicas entre União, Estados e Municípios.

Ao discutir a questão, Camargo (2001) considera que,

[...] pela primeira vez na história do federalismo no mundo, deu status constitucional aos municípios, reconhecendo sua existência como ente federativo em igualdade de condições com os Estados. Rompeu-se assim, a tradição constitucionalista do federalismo dual, de inspiração americana, inaugurando o federalismo tripartite, definido pelo jurista Miguel Reale como federalismo trino (p. 313).

Essa forma de organização política necessita da adesão de Estados e Municípios, com vistas à superação do modelo oligárquico (que historicamente fundamentou as ações políticas no Brasil) e à efetivação da democracia local, de forma a enfrentar as resistências de grupos conservadores, presentes na realidade brasileira e que mostram todo o seu poder em contextos menores da federação (ABRUCIO, 2005).

Em que pese o avanço da organização político-administrativa do país, não há como deixar de considerar que ainda sobrevivem "[...] resquícios culturais e políticos antirrepublicanos no plano local" (ABRUCIO, 2005, p. 49) e que "[...] diversas municipalidades do país ainda são governadas sob o registro oligárquico, em oposição ao modo poliárquico que é fundamental para a combinação entre descentralização e democracia" (ABRUCIO, 2005, p. 49). 
No entanto, não há como deixar de considerar que a Constituição Republicana de 1988 inaugurou o que Camargo (2001, p. 313) denomina de federalismo "municipalista e participativo", visando melhorar as políticas locais, reduzir as desigualdades sociais e fortalecer a sociedade civil e consolidar a cidadania. Os dispositivos constitucionais indicam e fortalecem a visão descentralizadora da administração pública, distribuindo competências entre os entes federados (algumas privativas, conforme estabelecido nos artigos 21,22, 25 e 30; e outras concorrentes, conforme previsto nos artigos 23 e 24). As competências concorrentes previstas no artigo 23 colocam os municípios em situação de igualdade institucional com os Estados e a União. Contudo, o exercício da igualdade institucional prevista precisa, nas realidades locais, ser respaldado no processo de autonomia para atuar no âmbito de sua competência. Infelizmente, a autonomia municipal ainda não é realidade na maioria dos municípios brasileiros.

Além da previsão do artigo 211 da Carta Magna, conforme mencionado, a legislação infraconstitucional dispõe, no parágrafo único do artigo 11 da Lei ${ }^{\circ}$ 9.394/96 (Lei de Diretrizes e Bases da Educação Nacional), que: “Os Municípios poderão optar, ainda, por se integrar ao sistema estadual de ensino ou compor com ele um sistema único de educação básica" (BRASIL, 1996, p. 27835). Segundo Sarmento (2005, p. 1354), "[...] a criação do sistema municipal de ensino é uma questão estreitamente relacionada ao pacto federativo no Brasil, indo além da política de municipalização, acentuada nos anos de 1990, firmando o município a sua autonomia".

É importante destacar que a inclusão de dispositivos legais que reconhecem a autonomia dos municípios para a elaboração de políticas locais, redistribuindo recursos e competências entre os entes federados, é resultado da correlação de forças evidenciadas no período final da ditadura militar e no processo de redemocratização posterior. Nesse contexto, destacam-se: a mobilização de grupos sociais e indivíduos no processo constituinte brasileiro, evidenciando a mobilização popular em prol de uma nova organização política e jurídica para o país; a criação da União Nacional dos Dirigentes Municipais de Educação (UNDIME), em 1986; a criação da União Nacional dos Conselhos Municipais de Educação (UNCME) 3 , em 1992; e o crescimento de associações, grupos e entidades dispostas a empreenderem ações de planejamento, execução, acompanhamento e avaliação das ações políticas. Tais fatos, e acontecimentos decorrentes, colaboraram para o debate a respeito da descentralização e da democratização da gestão pública, colaborando para que os municípios e os sujeitos locais recebessem

O Estatuto da UNCME prevê, dentre suas finalidades: "[...] incentivar e orientar a criação e organização de novos Conselhos Municipais de Educação, como uma das estratégias fundamentais para a organização dos Sistemas Municipais de Educação" (conforme inciso VI do art. $3^{\circ}$ ) - (UNCME, 2008, p. 1). 
responsabilidades que colaborassem no processo participativo local, com vistas à melhoria das condições de vida de toda a população. No contexto do processo constituinte do período, Sarmento (2005) ressalta:

Pode-se perceber um aumento da ação dos municípios para garantir recursos e espaços de participação na defesa dos interesses locais, sendo possível entender o reconhecimento do município como ente jurídico autônomo na Constituição de 1988 como uma conquista (p. 1372).

As normas constitucionais e infraconstitucionais que contribuíram para a elevação dos municípios ao patamar de ente federado autônomo, capaz de criar, organizar e fazer funcionar um SME, possibilitaram, nas realidades locais, o planejamento e a realização de projeto próprio de desenvolvimento educacional. Assim, entende-se que a existência de SME pode indicar ${ }^{4}$ a vontade política e social em promover e ampliar a participação da sociedade na gestão da educação municipal.

Segundo a indicação legal no âmbito nacional, não resta dúvida de que o Município é autônomo para mobilizar esforços para a criação de sistema próprio de ensino, ultrapassando a simples previsão legal e tornando-a real. Para tanto, entende-se que se torna necessário respeitar alguns trâmites políticos e legais que possibilitem o reconhecimento social e jurídico sobre a existência de SME: a) criação do SME por meio de Lei Municipal específica: b) criação ou reorganização do CME, de modo que se torne o órgão normativo do SME; c) organização de aparato administrativo que possibilite a operacionalização do SME (previsão e destinação de recursos financeiros, estruturais e humanos); e, por fim, d) comunicação à Secretaria Estadual e ao Conselho Estadual de Educação sobre a aprovação das Leis específicas, visando oficializar sua desvinculação do SME (em razão de que, historicamente, os municípios e suas escolas compunham o Sistema Estadual de Ensino).

Tendo o processo democrático como mola propulsora para o avanço da educação municipal, a criação de SME precisa passar pelo crivo da sociedade, ou seja, a elaboração, a discussão e a aprovação de Lei Municipal precisam fomentar o debate a respeito dos limites e das possibilidades locais para implementar o desenvolvimento educacional da educação (pública e privada) do município. Nessa perspectiva, é bom lembrar que o SME é composto não apenas pelas "[...]

4 Entende-se, aqui, que a existência de SME pode indicar e não garantir o maior envolvimento da sociedade civil na gestão pública em razão do histórico de dominação política, econômica e cultural que permeiam as relações locais. 
instituições do ensino fundamental, médio e de educação infantil mantidas pelo poder público municipal”, mas também pelas "[...] instituições de educação infantil criadas e mantidas pela iniciativa privada" e pelos "órgãos municipais de educação", conforme estabelecido pelos incisos I, II e III do artigo 18 da Lei $\mathrm{n}^{\circ}$ 9.394/96 (BRASIL, 1996, p. 27835). Assim, desde o processo de elaboração até a aprovação da Lei Municipal, a participação precisa ser fomentada, visto que tal lei compromete e responsabiliza diferentes sujeitos e instituições. A responsabilização coletiva pelo funcionamento do SME pode conduzir a uma participação em prol de interesses comuns.

Além disso, o artigo 11 da Lei n ${ }^{\circ}$ 9.394/96 imputa aos municípios a responsabilidade por "[...] baixar normas complementares para seu sistema de ensino" e "[...] autorizar, credenciar e supervisionar os estabelecimentos do seu sistema de ensino" (BRASIL, 1996, p. 27835), conforme incisos III e IV, respectivamente. Para baixar normas complementares, há necessidade de um órgão normativo, que se materialize no CME. Para tanto, esse órgão necessita ter funções que o autorizem a estabelecer normas, além de acompanhar e fiscalizar seu cumprimento no âmbito municipal. Por isso, o CME, organizado e dotado de autonomia, pautado em práticas democráticas que superem interesses de classe, é tão importante para o funcionamento do SME.

Assim, a constituição de SME deveria evidenciar a vontade coletiva dos cidadãos para o envolvimento no planejamento, no acompanhamento e na fiscalização das ações político-educacionais, tanto aquelas voltadas à oferta pública quanto privada. No entanto, é preciso ressaltar que a vivência da democracia no Brasil ainda é marcada por sua história político-social, visto que, em raros momentos, a população teve a oportunidade de experimentar práticas verdadeiramente democráticas, dado que os momentos participativos vividos sempre estiveram vinculados a interesses de determinados grupos que visavam à perpetuação de seu domínio.

No contexto paranaense, a criação de SME ainda é bastante tímida se comparada a outros estados da Região Sul, posto que, em 2007, o Rio Grande do Sul já contava com 37\% dos municípios com Leis de SME editadas (WERLE; THUM; ANDRADE, 2010); Santa Catarina contava com 58\% (SANTOS, 2012) e em pesquisa recente Nardi (2018) indica que o estado conta com 95\% dos municípios com Sistemas de Ensino instituídos. No Paraná, a organização de SME iniciou no ano de 2001. Atualmente, apenas $4 \%$ dos municípios paranaenses já constituíram sistemas próprios de Ensino e os demais continuam vinculados ao Sistema Estadual, conforme demonstrado na Tabela 1. 
Essa realidade indica, por um lado, a força política do Governo Estadual (independentemente da pessoa ou partido político), que detém o controle sobre a organização do ensino no estado, sendo, consequentemente, hegemônico em relação aos encaminhamentos dados à política educacional como um todo; e, por outro lado, evidencia a fragilidade dos governos locais em constituir-se em gestor autônomo em relação à educação. Os municípios paranaenses que já aprovaram leis municipais para a criação de Sistema de Ensino próprio são demonstrados no Quadro 1.

Tabela 1 - Vinculação dos municípios aos sistemas de ensino. Paraná, 2016

\begin{tabular}{lcc}
\hline $\begin{array}{l}\text { Total de Municípios no } \\
\text { Estado }\end{array}$ & $\begin{array}{c}\text { Municípios com Sistema } \\
\text { Municipal de Ensino }\end{array}$ & $\begin{array}{c}\text { Municípios vinculados ao } \\
\text { Sistema Estadual de Ensino }\end{array}$ \\
\hline 399 & 16 & 383 \\
$100 \%$ & $4 \%$ & $96 \%$ \\
\hline
\end{tabular}

Fonte: Elaborada pela autora (2016) a partir de dados das Prefeituras e Câmaras Municipais dos 399 Municípios do Paraná

Quadro 1 - Municípios paranaenses com sistemas de ensino legalmente intituídos, 2016

\begin{tabular}{|c|c|c|}
\hline Ano & Município & Lei Municipal de criação do Sistema \\
\hline 2001 & Chopinzinho & Lei $n^{\circ} 02$, de 20 de dezembro de 2001 \\
\hline \multirow[t]{3}{*}{2002} & Toledo & Lei $\mathrm{n}^{\circ} 1.857$, de 18 de dezembro de 2002 \\
\hline & Londrina & Lei $n^{\circ}$ 9.012, de 23 de dezembro de 2002 \\
\hline & Ponta Grossa & Lei $\mathrm{n}^{\circ} 7.081$, de 30 de dezembro de 2002 \\
\hline \multirow[t]{4}{*}{2004} & Ibiporã & Lei $n^{\circ} 1.891$, de 30 de junho de 2004 \\
\hline & São José dos Pinhais & Lei $n^{\circ} 632$, de 29 de outubro de 2004 \\
\hline & Guarapuava & Lei $n^{\circ} 1.394$, de 8 de outubro de 2004 \\
\hline & Araucária & Lei $n^{\circ} 1.528$, de 2 de dezembro de 2004 \\
\hline 2006 & Curitiba & Lei $\mathrm{n}^{\circ} 12.090$, de 19 de dezembro de 2006 \\
\hline 2007 & Paranaguá & Lei $n^{\circ} 69$, de 10 de setembro de 2007 \\
\hline 2008 & Sarandi & Lei $n^{\circ} 1.531$, de 16 de junho de 2008 \\
\hline 2009 & Pinhais & Lei $n^{\circ} 1.059$, de 28 de dezembro de 2009 \\
\hline 2010 & Cascavel & Lei $n^{\circ}$ 5.694, de 22 de dezembro de 2010 \\
\hline \multirow[t]{2}{*}{2013} & Iguatu & Lei $n^{\circ} 620$, de 3 de abril de 2013 \\
\hline & Palmeira & Lei $n^{\circ} 3.592$, de 13 de dezembro de 2013 \\
\hline 2016 & Telêmaco Borba & Lei $n^{\circ} 2.153$, de 24 de outubro de 2016 \\
\hline
\end{tabular}

Fonte: Elaborado pela autora (2016) a partir de dados das Prefeituras e Câmaras Municipais pesquisadas 
Após declararem sua autonomia por meio de lei específica, a composição dos CME e as relações internas que permeiam a normatização da educação podem representar possibilidades ou limites para a efetivação do princípio da gestão democrática. As possibilidades podem ocorrer em razão da ampliação da participação de diferentes segmentos, em especial daqueles que necessitam da educação pública e são diretamente atingidos pelas decisões do órgão, enquanto que os limites podem ocorrer em razão do atrelamento aos interesses dominantes, sem que o princípio da gestão democrática se faça presente.

Sobre questão similar, e avançando para a ingerência política, em investigação a respeito do funcionamento, durante quatro décadas, do Conselho Estadual do Rio de Janeiro, Vasconcelos, Almeida e Peixoto (2017) apontam para uma linha descendente de atuação e representatividade do órgão, conforme interesses políticos de cada período da gestão estadual, fato que indica a falta de autonomia do CEE/RJ e descontinuidade de políticas para o setor normativo. Essa questão também pode ser observada em diferentes contextos municipais, não sendo muito diferente da realidade aqui exposta.

\section{A composição dos Conselhos Municipais de Educação: relações com a gestão democrática}

Em que pese à organização de SME evidenciar a vontade política dos gestores municipais em validar a autonomia para com a oferta da educação no contexto local, a questão é bastante complexa, visto que necessita de certo planejamento em curto, médio e longo prazo para o funcionamento eficiente dos órgãos normativo e executivo do sistema. Quando o Governo Municipal decide pela organização de seu próprio Sistema de Ensino, ele precisa atentar para algumas ações imprescindíveis para colocá-lo em funcionamento adequado, conforme já citado anteriormente. Além disso, o CME tem, como órgão normativo, latente a materialização da gestão democrática nos contextos locais, caracterizando-se como órgão contraditório que baliza diferentes interesses e compromissos sociais, políticos e econômicos, conforme sua organização e as relações que permeiam as decisões a serem tomadas em seu interior.

Para a discussão aqui proposta, demonstramos que, em relação aos municípios paranaenses que já constituíram sistema próprio de Ensino (16), quatro instituíram CME entre os anos de 1985 e 1997 (Curitiba, 1985; Ponta Grossa, 1985; São José dos Pinhais, 1993, Iguatu, 1997). Os demais somente o fizeram ao constituírem Sistemas Municipais de Ensino a partir de 2001 (Chopinzinho, em 2001; Toledo, em 2002; Londrina, em 2002; Ibiporã, Guarapuava e Araucária, em 2004; Paranaguá e Telêmaco Borba, em 2007; Sarandi, em 2008; Pinhais, em 2009; Cascavel, em 2010; e Palmeira, em 2013). 
Sendo órgão representativo dos interesses do Estado em determinado momento histórico, o CME é composto por diferentes segmentos da sociedade civil e da sociedade política, congregando forças sociais e políticas que estarão em constante disputa em razão da visão de mundo, de sociedade e, consequentemente, de educação de seus membros e dos segmentos representados. Dependendo da visão de mundo e de sociedade que se almeja, serão as defesas de seus membros e, por conseguinte, das decisões tomadas coletivamente que poderão vincular-se à manutenção ou à transformação da realidade vivida.

A composição do CME pode representar a ampliação da participação e do debate a respeito de assuntos educacionais, visto que possibilita que diferentes posicionamentos sejam confrontados e que o exercício democrático deixe de ser previsto apenas formalmente para se tornar realidade. Quando isso acontece, o CME torna-se progressista e a gestão democrática torna-se real. Entretanto, a democracia almejada e discursada pode tornar-se um engodo, caso esses órgãos colegiados de representação social e política sejam compostos por indicação viciada de membros, a qual amplia burocraticamente a participação, sem considerar a essência da democracia, podendo ser considerada como gestão democrática formal. Quando a composição ocorre dessa maneira, o CME pode tornar-se apenas executor, legitimador das ações governamentais, funcionando de forma burocrática e reacionária ${ }^{5}$.

Tendo como pressuposto que a gestão democrática de caráter progressista é aquela que tem possibilidade de colaborar na formação coletiva dos conselheiros e interferir de maneira significativa na condução das políticas de educação nos municípios, seja por meio de propostas, normas ou acompanhamento das ações governamentais, entende-se que é imprescindível a ampliação da participação de diferentes segmentos da sociedade, principalmente daqueles segmentos que serão atingidos pelas deliberações colegiadas, ou seja, daqueles que trabalham e aprendem na escola pública. Esse posicionamento sobre a participação das classes populares em órgãos colegiados corrobora a defesa de Gramsci (2004, p. 103) que "[...] a filosofia da práxis não busca manter os 'simples' na sua filosofia primitiva do senso comum, mas busca, ao contrário, conduzi-los a uma concepção de vida superior". Por isso, para a análise, tomamos como referência a composição desses órgãos normativos, por meio dos segmentos representados, conforme apresentado na Tabela 2, a seguir.

\footnotetext{
Para a caracterização de um Conselho Municipal de Educação como progressista ou reacionário, tomamos emprestadas as reflexões de Antonio Gramsci sobre as funções dos partidos políticos. A esse respeito Gramsci esclarece que "[...] o funcionamento de um dado partido fornece critérios discriminantes: quando o partido é progressista, funciona 'democraticamente' (no sentido de um centralismo democrático); quando o partido é reacionário, funciona 'burocraticamente' (no sentido de centralismo burocrático). Neste segundo caso, o partido é puro executor, não deliberante: ele, então, é tecnicamente um órgão de polícia e seu nome de partido político é pura metáfora de caráter mitológico" (GRAMSCI, 2007, p. 308).
} 
Tabela 2 - Composição dos órgãos normativos dos sistemas municipais de ensino, CME. Paraná, 2016

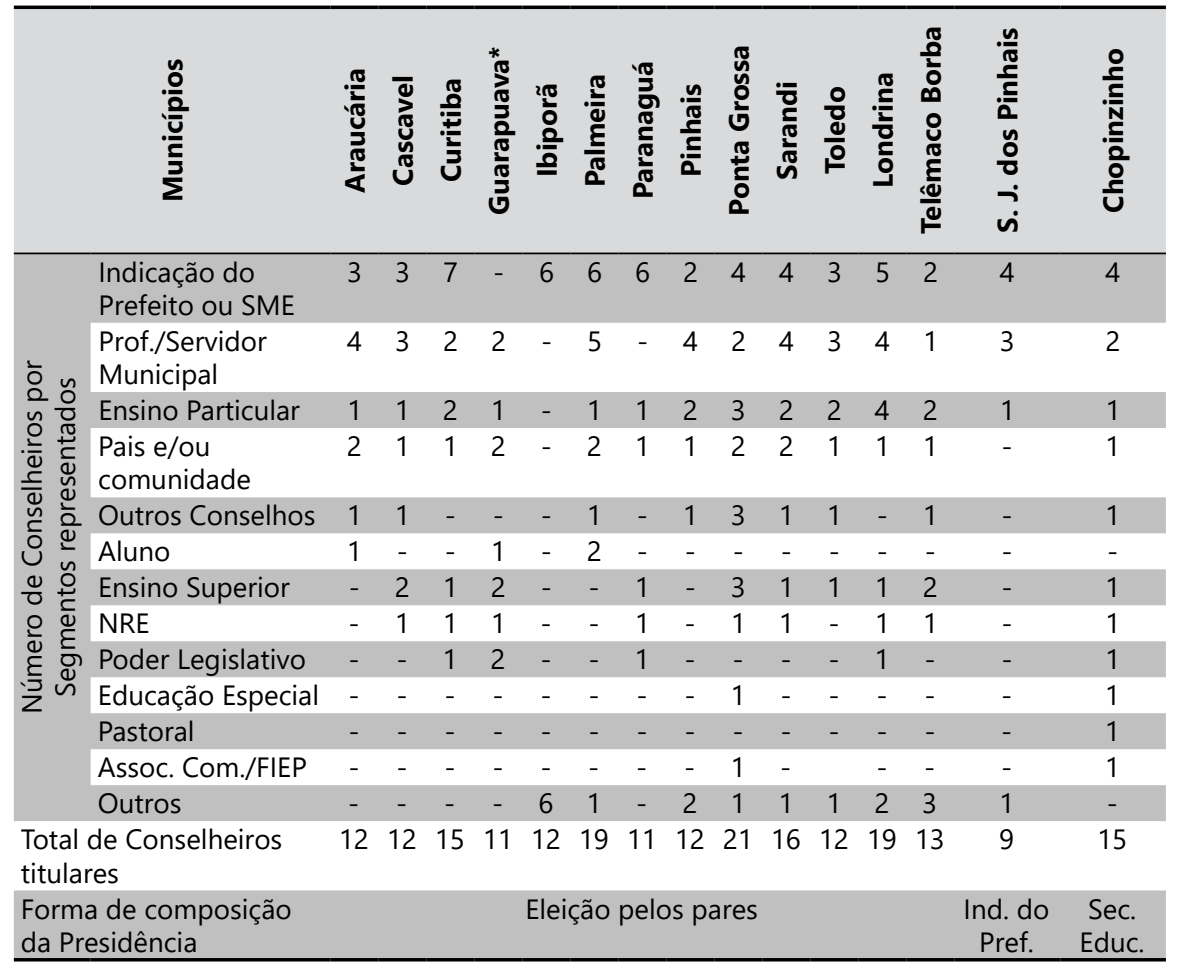

Fonte: Elaborada pela autora (2016) a partir das leis que tratam da organização dos Conselhos Municipais de Educação nos respectivos municípios

* Indicação por lista tríplice para posterior indicação do Prefeito.

O que se evidencia nos dados levantados é que, em todos os municípios, a indicação de membros que representem o Governo Municipal se faz presente, seja pelo Prefeito ou Secretário de Educação (note-se que, no município de Guarapuava, todos os representantes são indicados em lista tríplice para posterior nomeação pelo Prefeito Municipal, indicando, dessa forma, a prevalência dos interesses político-partidários na composição do órgão). Ressalta-se, ainda, que, com exceção ao município de Araucária, em todos os demais a representação do Governo Municipal é a maior em relação a todos os demais segmentos. Essa composição pode indicar a interferência do poder público local nas discussões e nas decisões, dificultando a efetivação da gestão democrática no âmbito dos órgãos colegiados. 
Sobre a possível ingerência dos gestores públicos municipais no funcionamento dos CME, destaca-se ainda que, em dois municípios, a presidência fica sob a responsabilidade do Poder Público Municipal (em São José dos Pinhais, a presidência é indicada pelo Prefeito, e, em Chopinzinho, é exercida pelo Secretário Municipal de Educação), sem a possibilidade de escolha entre os pares, fato que pode interferir na autonomia e nas ações democráticas do CME. Ainda é possível observar que a representação de movimentos sociais é praticamente nula, podendo estar inserida no segmento "Pais e Comunidade", mas sem a garantia de que estejam efetivamente representados. A possibilidade de participação de segmentos que, historicamente, estiveram à margem das decisões políticas desperta a

[...] consciência de fazer parte de uma determinada força hegemônica (isto é, a consciência política) é a primeira fase de uma ulterior e progressiva autoconsciência, na qual teoria e prática finalmente se unificam. Portanto, também a unidade de teoria e prática não é um dado de fato mecânico, mas um devir histórico, que tem a sua fase elementar e primitiva no sentimento de "distinção", de "separação", de independência quase instintiva, e progride até a aquisição real e completa de uma concepção do mundo coerente e unitária (GRAMSCI, 2004, p. 103-104).

Desse modo, a composição do CME, em uma perspectiva de gestão democrática progressista, contribui significativamente para a compreensão da realidade, por meio de um processo que forma para o exercício democrático e transforma a coletividade, munindo-a de argumentos para a defesa dos interesses coletivos.

\section{Considerações Finais}

A organização de SME no Paraná, apesar de tímida, indica possibilidades de efetivação da gestão democrática nas políticas educacionais locais, visto que possibilita a participação e o debate de diferentes segmentos nas escolhas para a melhoria da educação municipal. A gestão democrática não se institui por lei ou por determinação governamental, mas é desenvolvida na experiência prática, sendo necessário o desenvolvimento de consciência coletiva.

Uma consciência coletiva, ou seja, um organismo vivo só se forma depois que a multiplicidade se unifica através do atrito dos indivíduos: e não se pode dizer que o "silêncio" não seja multiplicidade. Uma orquestra que ensaia, cada instrumento por sua conta, dá a impressão da mais horrível cacofonia; porém, estes ensaios são a condição para que a orquestra viva como um só "instrumento" (GRAMSCI, 2007, p. 333). 
Por isso, a organização de SME e CME, deliberativos e propositivos, pode colaborar para o desenvolvimento coletivo com vistas a práticas democráticas que vão além da representatividade formal prevista na democracia liberal, indicando possibilidades de interferir nos rumos das políticas e das realidades locais.

Nessa perspectiva, a gestão democrática no interior dos SME precisa ser entendida para além da determinação legal, de forma a evidenciar tanto suas possibilidades quanto seus limites no âmbito da gestão educacional. Destarte, a questão não se fecha em análises parciais, mas demonstra a emergência de aprofundar a discussão a respeito, visando apreender o máximo das determinações da realidade. 


\section{Democratic management in municipal education systems of Paraná: an analysis from the municipal councils of education}

\section{Abstract}

This text discusses democratic management in the Municipal Councils of Education of the municipalities of Paraná that constituted their own education systems and aims to demonstrate how the normative organs are composed and what the possibilities and limits of democratic participation in the local contexts are. In order to do so, having as a theoretical and methodological assumption the historical and dialectical materialism, this paper discusses the municipal autonomy to conduct the education under its responsibility and analyzes the composition of the Municipal Councils of Education of the municipalities that have already instituted their own education systems. The analyses show that the composition of the Municipal Councils of Education is characterized as a possibility of democratic exercise, but the limits are also present, indicating links with the hegemonic interests that guide local policies.

Keywords: Municipal Education System. Municipal Councils of Education. Democratic management. Education policies.

\section{La gestión democrática en los sistemas municipales de enseñanza de Paraná: un análisis a partir de los consejos municipales de educación}

\section{Resumen}

En este artículo se discute la gestión democrática en los Consejos Municipales de Educación de los municipios paranaenses que constituyeron los sistemas propios de Enseñanza y tiene por objetivo demonstrar cómo los organismos reguladores están compuestos y cuáles son las posibilidades y los límites de participación democrática en los contextos locales. Para ello, teniendo como supuesto teórico y metodológico el materialismo histórico y dialéctico, en el artículo se discute la autonomía municipal para la conducción de la educación bajo su responsabilidad y analiza la composición de los Consejos Municipales de Educación de los municipios que ya han establecido sistemas propios de Enseñanza. Los análisis demuestran que la composición de los Consejos Municipales de Educación se caracteriza como una posibilidad para el ejercicio democrático, pero los límites también están presentes indicando la vinculación con los intereses hegemónicos que guían las politicas locales.

Palabras clave: Sistema Municipal de Enseñanza. Consejos Municipales de Educación. Gestión democrática. Políticas Educativas. 


\section{Referências}

ABRUCIO, F. L. A coordenação federativa no Brasil: a experiência do período FHC e os desafios do governo Lula. Revista de Sociologia e Política, Curitiba, n. 24, p. 41-67, jun. 2005. https://doi.org/10.1590/S0104-44782005000100005

ARAUCÁRIA. Lei $\mathrm{n}^{\circ} 1.528$, de 2 de dezembro de 2004. Institui o sistema municipal de ensino de Araucária e dá outras providências. Diário Oficial do Município, Araucária, 3 dez. 2004.

BRASIL. Lei n ${ }^{\circ}$ 9.394, de 20 de dezembro de 1996. Estabelece as diretrizes e bases da educação nacional. Diário Oficial da União, Brasília, DF, 23 dez. 1996.

CAMARGO, A. Federalismo e identidade nacional. In: SACHS, I.; WILHEIM, J.; PINHEIRO, P. S. Brasil: um século de transformações. São Paulo: Companhia das Letras, 2001. p. 306-347.

CASCAVEL. Lei $\mathrm{n}^{\circ}$ 5.694, de 22 de dezembro de 2010. Organiza o sistema municipal de ensino e cria o conselho municipal de educação de Cascavel. Diário Oficial do Município, Cascavel, 24 dez. 2010.

CHOPINZINHO. Lei complementar $\mathrm{n}^{\circ}$ 2, de 20 de dezembro de 2001. Autoriza o chefe do poder executivo a criar o sistema municipal de ensino de Chopinzinho. Diário Oficial do Município, Chopinzinho, 21 dez. 2001.

CURITIBA. Lei n ${ }^{\circ} 12.090$, de 19 de dezembro de 2006. Dispõe sobre a organização do sistema municipal de ensino. Diário Oficial do Município, Curitiba, 20 dez. 2006.

CURY, C. R. J. Sistema nacional de educação: desafio para uma educação igualitária. Educação \& Sociedade, Campinas, v. 29, n. 105, p. 1187-209, set./ dez. 2008. https://doi.org/10.1590/S0101-73302008000400012

GRAMSCI, A. Cadernos do cárcere. 3. ed. Rio de Janeiro: Civilização Brasileira, 2004. v. 1.

GRAMSCI, A. Cadernos do cárcere. 3. ed. Rio de Janeiro: Civilização Brasileira, 2007. v. 3.

GUARAPUAVA. Lei ${ }^{\circ} 1.394$, de 8 de outubro de 2004. Disciplina a organização do sistema municipal de ensino do município de Guarapuava, e dá outras providências. Diário Oficial do Município, Guarapuava, 9 out. 2004. 
IBIPORÃ. Lei no 1.891 , de 30 de junho de 2004. Disciplina a organização do sistema municipal de ensino do Município de Ibiporã e dá outras providências. Diário Oficial do Município, Ibiporã, 1 jul. 2004.

IGUATU (PR). Lei $\mathrm{n}^{\circ}$ 620, de 3 de abril de 2013. Institui o sistema municipal de ensino do Município de Iguatu, e dá outras providências. Diário Oficial do Município, Iguatu, 4 abr. 2013.

LAGARES, R. Organização da educação municipal no Tocantins: entre a conservação de redes e o processo efetivo de institucionalização de sistemas. 2008. Tese (Doutorado em Educação) - Faculdade de Educação, Universidade Federal de Goiás, Goiânia, 2008.

LONDRINA. Lei $\mathrm{n}^{\circ}$ 9.012, de 23 de dezembro de 2002. Cria e organiza o sistema de ensino do Município de Londrina e o conselho municipal de educação. Diário Oficial do Município, Londrina, 24 dez. 2002.

NARDI, E. Gestão democrática do ensino público na educação básica: dimensões comuns e arranjos institucionais sinalizados em bases normativas de sistemas municipais de ensino. Educar em Revista, Curitiba, v. 34, n. 68, p. 123-136, mar./abr. 2018. https://doi.org/10.1590/0104-4060.57218

PALMEIRA. Lei ${ }^{0}$ 3.592, de 13 de dezembro de 2013. Dispõe sobre a criação e organização do sistema municipal de ensino de Palmeira e dá outras providências. Diário Oficial do Município, Palmeira, 14 dez. 2013.

PARANAGUÁ. Lei complementar nº 69, de 10 de setembro de 2007. Dispõe sobre o sistema municipal de ensino do Município de Paranaguá e dá outras providências. Diário Oficial do Município, Paranaguá, 11 set. 2013.

PINHAIS. Lei $\mathrm{n}^{\mathrm{o}} 1.059$, de 28 de dezembro de 2009. Dispõe sobre a organização do sistema municipal de ensino do Município de Pinhais e dá outras providências. Diário Oficial do Município, Pinhais, 30 dez. 2009.

PONTA GROSSA. Lei $\mathrm{n}^{\circ}$ 7.081, de 30 de dezembro de 2002. Dispõe sobre a criação do sistema municipal de ensino. Diário Oficial do Município, Ponta Grossa, 2 jan. 2003.

SANTOS, A. P. Gestão democrática nos sistemas municipais de ensino de Santa Catarina: implicações da avaliação em larga escala. 2012. Tese (Doutorado em Educação) - Escola de Humanidades, Universidade do Vale do Rio dos Sinos, São Leopoldo, 2012. 
SÃO JOSÉ DOS PINHAIS. Lei no 632, de 29 de outubro de 2004. Disciplina a organização do sistema municipal de ensino do Município de São José dos Pinhais. Diário Oficial do Município, São José dos Pinhais, 30 out. 2004.

SARANDI (PR). Lei ${ }^{\circ} 1.531$, de 16 de junho de 2008. Institui e regulamenta o sistema municipal de ensino de Sarandi, cria o conselho municipal de educação de Sarandi e dá outras providencias. Diário Oficial do Município, Sarandi, 17 jun. 2008.

SARMENTO, D. C. Criação dos sistemas municipais de ensino. Educação \& Sociedade, Campinas, v. 26, n. 93, p. 1363-1390, set./dez. 2005. https://doi.org/10.1590/S0101-73302005000400016

SCHLESENER, A. H. Gestão democrática da educação e formação de conselhos escolares. In: FERREIRA, N. S. C. (org.). Políticas públicas e gestão da educação: polêmicas, fundamentos e análises. Brasília, DF: Liber Livro, 2011. p. 173-185.

SENADO FEDERAL. Constituição da República Federativa do Brasil. Brasília, DF, 1988.

SOARES, E. L. Gestão democrática: uma análise das bases normativas dos sistemas municipais de educação do Maranhão. 2017. 189 f. Dissertação (Mestrado em Educação) - Universidade Federal do Maranhão, São Luís, 2017.

TELÊMACO BORBA. Lei n ${ }^{\circ} 2.153$, de 24 de outubro de 2016. Organiza o conselho municipal de educação e institui o sistema municipal de ensino de Telêmaco Borba e dá outras providências. Diário Oficial do Município, Telêmaco Borba, 25 out. 2016.

TOLEDO. Lei $\mathrm{n}^{\mathrm{o}} 1.857$, de 18 de dezembro de 2002. Institui o sistema municipal de ensino de Toledo. Diário Oficial do Município, Toledo, 28 dez. 2003.

UNIÃO NACIONAL DOS CONSELHOS MUNICIPAIS DE EDUCAÇÃO Uncme. Estatuto da União Nacional dos Conselhos Municipais de Educação. Florianópolis, 2008. Disponível em: http://www.uncme.com.br/upload/ galeria/825/ESTATUTO\%20UNCME.pdf. Acesso em: 23 mar. 2017.

VASCONCELOS, M. C. C.; ALMEIDA, N. N.; PEIXOTO, L. F. Conselho estadual de educação do Rio de Janeiro: heranças, marcos legais e limites políticos de um órgão do estado. Ensaio: Avaliação e Políticas Públicas em Educação, Rio de Janeiro, v. 25, n. 96, p. 701-720, jul./set. 2017. https://doi.org/10.1590/s0104-40362017002501290 
WERLE, F. O. C.; THUM, A. B.; ANDRADE, A. C. Sistemas municipais de ensino no Rio Grande do Sul: uma contribuição para as políticas educacionais. Revista Brasileira de Política e Administração da Educação, Porto Alegre, v. 26, n. 2, p. 377-393, maio/ago. 2010. https://doi.org/10.21573/vol26n22010.19723

WOOD, E. M. Democracia contra o capitalismo: a renovação do materialismo histórico. São Paulo: Boitempo, 2006.

\section{Informações da autora}

Simone de Fátima Flach: Doutora em Educação pela Universidade Federal de São Carlos. Pós-Doutorado em Educação pela Universidade Tuiuti do Paraná. Professora do Departamento de Educação e do Programa de Pós-Graduação em Educação da Universidade Estadual de Ponta Grossa. Contato: eflach@uol.com.br

iD https://orcid.org/0000-0002-9445-0111 